\title{
Characteristics and sources of gravity waves observed in noctilucent cloud over Norway
}

\author{
T. D. Demissie ${ }^{1,2}$, P. J. Espy ${ }^{1,2}$, N. H. Kleinknecht ${ }^{1}$, M. Hatlen ${ }^{1}$, N. Kaifler ${ }^{3}$, and G. Baumgarten ${ }^{3}$ \\ ${ }^{1}$ Norwegian University of Science and Technology (NTNU), Department of Physics, Trondheim, Norway \\ ${ }^{2}$ Birkeland Centre for Space Science, Bergen, Norway \\ ${ }^{3}$ Leibniz-Institut für Atmosphärenphysik e. V., 18225 Kühlungsborn, Germany
}

Correspondence to: T. D. Demissie (teferi.demissie@uni.no)

Received: 12 August 2013 - Published in Atmos. Chem. Phys. Discuss.: 8 November 2013

Revised: 29 September 2014 - Accepted: 6 October 2014 - Published: 18 November 2014

\begin{abstract}
Four years of noctilucent cloud (NLC) images from an automated digital camera in Trondheim and results from a ray-tracing model are used to extend the climatology of gravity waves to higher latitudes and to identify their sources during summertime. The climatology of the summertime gravity waves detected in NLC between 64 and $74^{\circ} \mathrm{N}$ is similar to that observed between 60 and $64^{\circ} \mathrm{N}$ by Pautet et al. (2011). The direction of propagation of gravity waves observed in the NLC north of $64^{\circ} \mathrm{N}$ is a continuation of the north and northeast propagation as observed in south of $64^{\circ} \mathrm{N}$. However, a unique population of fast, short wavelength waves propagating towards the $\mathrm{SW}$ is observed in the NLC, which is consistent with transverse instabilities generated in situ by breaking gravity waves (Fritts and Alexander, 2003). The relative amplitude of the waves observed in the NLC Mie scatter have been combined with raytracing results to show that waves propagating from near the tropopause, rather than those resulting from secondary generation in the stratosphere or mesosphere, are more likely to be the sources of the prominent wave structures observed in the NLC. The coastal region of Norway along the latitude of $70^{\circ} \mathrm{N}$ is identified as the primary source region of the waves generated near the tropopause.
\end{abstract}

\section{Introduction}

Gravity waves contribute strongly to the global dynamics, circulation, structure, variability and thermal balance of the atmosphere. They can be generated in the lower atmosphere through topography, convection and wind shear, and prop- agate upward into the middle and upper atmosphere (Fritts and Alexander, 2003, and reference therein). Their amplitude grows with altitude due to the exponential decrease of the atmospheric density with height. In the mesosphere the waves can become unstable and break, dissipating their energy and depositing their momentum locally (Lindzen, 1981; Holton, 1983; Garcia and Solomon, 1985). The filtering of wave energy by the stratospheric background wind modulates the gravity wave flux into the mesosphere and the momentum deposition. In winter time, eastward propagating gravity waves are mostly blocked by the strong eastward winds in the stratosphere, and a net westward momentum will be deposited in the mesosphere that creates a poleward convergent and downward flow. At the summer pole, the westward stratospheric winds lead to eastward momentum deposition and hence a divergent and upward flow. This establishes a pole-to-pole circulation in the mesosphere (Lindzen 1981; Holton, 1982, 1983; Garcia and Solomon, 1985) that drives the polar mesospheric temperatures adiabatically away from the radiative equilibrium and creates a cold summer and warm winter mesopause at high latitudes (Haurwitz, 1961; Garcia and Solomon, 1985; Lübcken et al., 1999; Fritts and Luo, 1995; Luo et al., 1995; Espy and Stegman, 2002; Fritts and Alexander, 2003). The cold polar summer mesosphere reaches temperatures below $150 \mathrm{~K}$, which is below the frost point for the small amount of water vapor that is present there. The resulting ice clouds that are formed are called noctilucent clouds (NLCs) when viewed from the ground, or polar mesospheric clouds (PMCs) when viewed from space. 
Since the thermal balance and the global circulation of the atmosphere are strongly determined by the gravity wave flux into the mesosphere, a correct representation of their effect is critical for global circulation models (GCMs). Longer scale gravity waves can be resolved explicitly in current GCMs. However, shorter-scale waves, which transport the major part of the momentum and energy to the mesopause (Vincent, 1984), have to be parameterized (Hamilton, 1996). For an adequate parameterization, sufficient knowledge of seasonal and latitudinal behavior of gravity waves, as well as their source regions, are essential (e.g., Rind et al., 1988; Hamilton, 1995), particularly in polar regions (Garcia and Boville, 1994; Hamilton, 1996).

Although there are a number of gravity-wave studies at high latitudes, most of these rely upon analyzing the wave structures induced by the waves in the night airglow (e.g., Taylor and Henriksen, 1989; Pautet et al., 2005; Nielsen et al., 2006, 2009; Espy et al., 2004; 2006, Suzuki et al., 2009; 2013). However, these observations are not possible during the high latitude polar summer when the mesosphere remains sunlit. Recently, Pautet et al. (2011) recognized that even though it is not possible to use the airglow during this period, the structures present in the NLC, known to be caused by gravity waves and their instabilities (Hines, 1960; Thomas, 1991; Fritts et al., 1993; Chandran et al., 2009, 2010), could themselves be used to infer the gravity waves present. Analyzing NLC images from Stockholm, Sweden $\left(59.5^{\circ} \mathrm{N}, 18.2^{\circ} \mathrm{E}\right)$, they were able to provide the first climatology of gravity-wave wavelengths, phase speeds and propagation directions from 60 to $64^{\circ} \mathrm{N}$ during the polar summer. Similarly, using observations from the Aeronomy of Ice in the Mesosphere (AIM) satellite, Taylor et al. (2011, and references therein) have compiled an impressive climatology of gravity-wave wavelengths and wave-front orientation from 75 to $85^{\circ} \mathrm{N}$ and $\mathrm{S}$ for waves with wavelengths $>20 \mathrm{~km}$.

We present here an extension of the Pautet et al. (2011) climatology to higher latitudes $\left(64\right.$ to $\left.74^{\circ} \mathrm{N}\right)$ using NLC images taken from Trondheim, Norway $\left(63.4^{\circ} \mathrm{N}, 10.5^{\circ} \mathrm{E}\right)$. In doing so, this study also fills the gap between the ground-based and satellite studies. In addition, we seek to expand those studies by characterizing the relative amplitude of the waves in the NLC and utilizing a ray-tracing model to identify the source regions of high latitude gravity waves present during the polar summer. Together, these observations provide a critical extension of the summertime gravity-wave climatology and information as to the efficiency of the different sources required for parameterization of gravity-wave effects.

\section{Observation and processing techniques of the NLC images}

Four years of NLC pictures, since the summer of 2007, have been collected using an automatic digital camera (Canon EOS 450D) from Trondheim, Norway by the Leibniz In- stitute of Atmospheric Physics of Kühlungsborn, Germany (Baumgarten et al., 2009b). The camera takes pictures throughout the twilight period with exposure times of 0.5 and $0.6 \mathrm{~s}$ depending on the solar elevation angle with a cadence ranging between two to three frames per minute. The camera points towards the north with a field of view (FOV) of $54.5 \times 41.5^{\circ}$.

Figure 1 is an example of an NLC image taken on the night of 16-17 July 2008, at 22:30 UT, which is 23:12 local solar time (LST). At this time, the Sun is in the north-northwest, towards the bottom and left of the image. The NLCs are clearly visible in the image when the solar Mie scattering from the clouds is brighter than the column-integrated Rayleigh scattered sunlight from the atmosphere. However, in the lower part of the image, towards the Sun, the clouds are not visible due to the loss of contrast against the atmospheric Rayleigh scatter. Similarly, they are not visible in the upper part of the image as the Sun no longer illuminates the clouds. In those areas where the clouds are visible, different types of structures with various forms and sizes are clearly seen in the sunlit NLC. This is the result of short-period gravity waves modulating the ice-particle density, and the resulting intensity fluctuations trace out the waves in the center and center right of the image. In addition, very small scale structures are visible that may be the result of instabilities that develop as the gravity waves begin to break (Fritts et al., 1993).

As a first step in the image analysis, the NLC images are mapped to a horizontal plane through the NLC layer "the satellite view" (Witt, 1962; Pautet and Moreels, 2002). In order to accurately project the NLC images, the viewing geometry of the camera, including the FOV, azimuth and elevation angles as well as rotation of the optical axis, were first calibrated using the visible stars that are manually identified in the images (Garcia et al., 1997). After the images were projected on a linear-scale grid using an optical ray tracer where the refractive index was calculated from air densities taken from MSISE-00. Each pixel of the camera was traced from the camera to the NLC altitude (Baumgarten et al., 2009a). Figure 2 is the processed NLC picture shown in Fig. 1, projected onto a latitude and longitude grid assuming an NLC average height of $83 \mathrm{~km}$ (e.g., Witt, 1962; Fiedler et al., 2009). These images were used to identify gravity-wave events and measure the wavelength, horizontal phase velocity, direction of propagation and relative intensity fluctuation of each event.

\section{The estimation of wave parameters}

\subsection{Estimation of wavelength and phase}

The next step was the wave analysis where individual wave events in the NLC images were visually identified. Within a sequence of images, organized structures propagating in a uniform direction for at least 20 min were identified as 


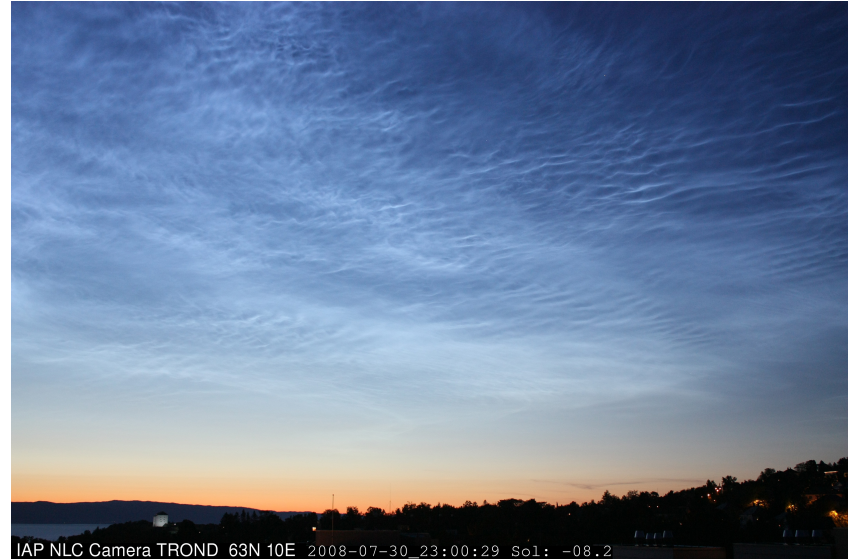

Figure 1. Noctilucent cloud observed by camera from Trondheim on 30 July 2008 at 23:00 UT.

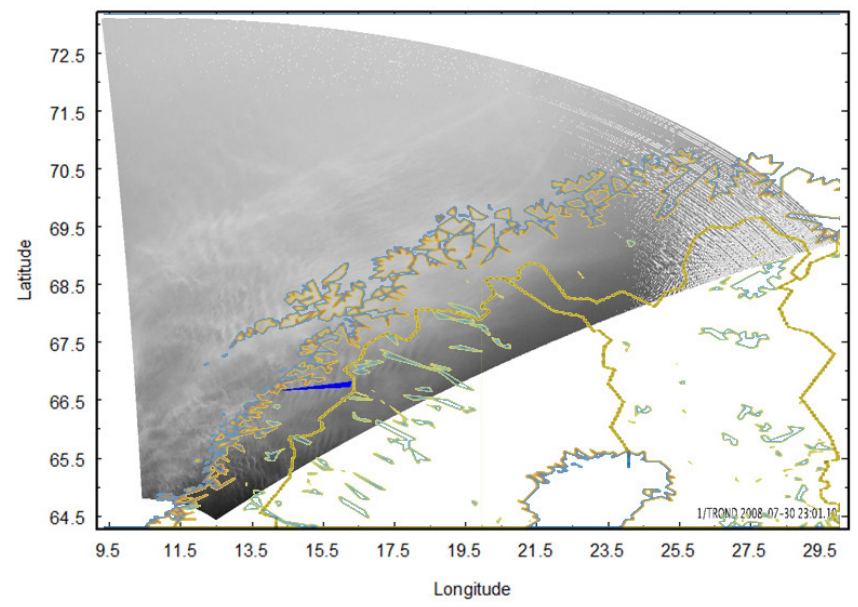

Figure 2. Image of the noctilucent cloud observed by camera from Trondheim on 30 July 2008 at 23:01 UT projected onto latitude and longitude (given in degrees).

gravity-wave events. Due to the short observational periods and challenging scattering conditions as well as bad weather conditions, a total of 34 such events were identified in this manner from the four summer observing seasons.

In order to infer the wave parameters, we have developed a robust method using a combination of fast Fourier transform (FFT) and a least squares fitting of a sinusoidal function of the intensity data in order to quantify the horizontal wavelength, phase speed and direction of propagation of the waves in the NLC images. This method is different from the 2-D FFT method used by Pautet et al. (2011), originally developed by Garcia et al. (1997), to analyze the gravity waves from the Stockholm NLC images. Although this fitting method is more labor intensive and more subjective than the Pautet et al. (2011) method, given the low contrast of these high latitude observations it was necessary to manually identify the wave parameters.
Since the images are mapped to an equally spaced latitude and longitude grid, the raw pixel values in the projected image are first converted into kilometer space. Once a wave structure has been visually identified in the NLC image, a line was drawn normal to the wave front. To ensure that the chosen line of sight was truly normal to the wave front, a series of profiles were extracted by slightly changing the angle of the line. The frequency (wavelength) of the wave pattern along each of these lines was determined using a Fourier transform technique. The line with the smallest wavelength is taken to be normal to the wave front (shown in Fig. 2 as an arrow) and is along the propagation direction of the wave. This line was then used for the analysis of the wave structure. In cases where there was more than one wavelength present, the largest wavelength was selected for analysis. In some cases, where the images are blurred or contaminated, the FFT of the difference image, i.e., the image formed by subtracting two adjacent images, provided the wavelength.

To determine the phase velocity of the wave, several consecutive images, i.e., time steps, of the same wave structure were analyzed. First a bias, linear slope and a sinusoid at the fixed, minimum wavelength determined above were fit to the intensity variations along the propagation direction. The bias and linear slope were then removed from the wave structure, and an FFT was applied to the de-trended intensity variations to determine the wavelength and phase of the wave structure along the propagation direction. The same procedure was carried out for all consecutive images to observe the change of the phase of the largest wavelength. It should be noted that the wavelength was determined only from the first image and held constant in all consecutive pictures. This is because other waves can propagate into the analysis regions and become the largest component of the wave structure. However, for the correct calculation of the phase values for each time step and hence the phase speeds of the wave it is important that the same wave is observed in all consecutive pictures. It should be noted that the phase velocity we derive in this analysis is the horizontal phase velocity, which, unlike the intrinsic phase velocity, is not Doppler shifted by the background wind (Hines et al., 1993, Marks and Eckermann, 1995). Figures 3 and 4 show an example of the Hovmöller diagrams of the raw data and the extracted wave structure along the propagation direction for consecutive time steps. The Hovmöller diagram shows wave along its direction of propagation at different time slices. This lets the wave coherency and propagation direction to be determined.

\subsection{Extracting the amplitudes}

In order to compare with gravity wave ray-tracing results, it is necessary to have an estimate of the relative amplitude of the waves present in the NLC. Particles can take hours to grow to visible sizes, but evaporation times approach seconds when temperatures are raised (Gadsden and Schröder, 1989). Thus, while the long-term effect of short-period waves 


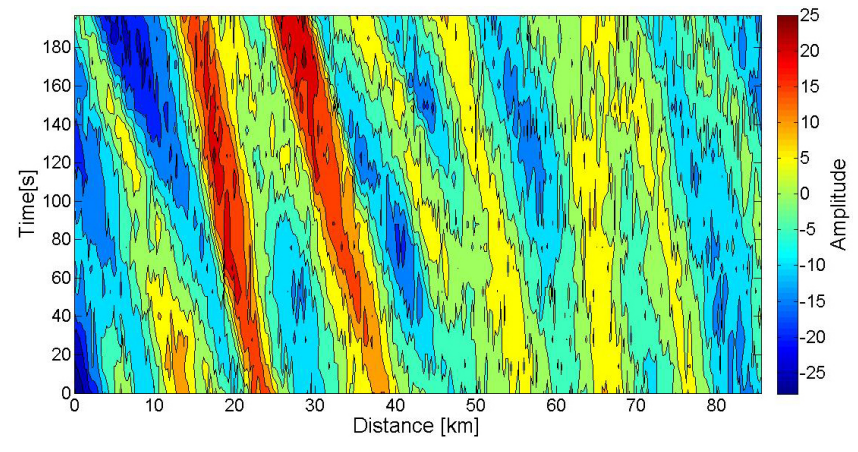

Figure 3. Hovmöller diagrams of the raw data along the propagation direction for consecutive time steps.

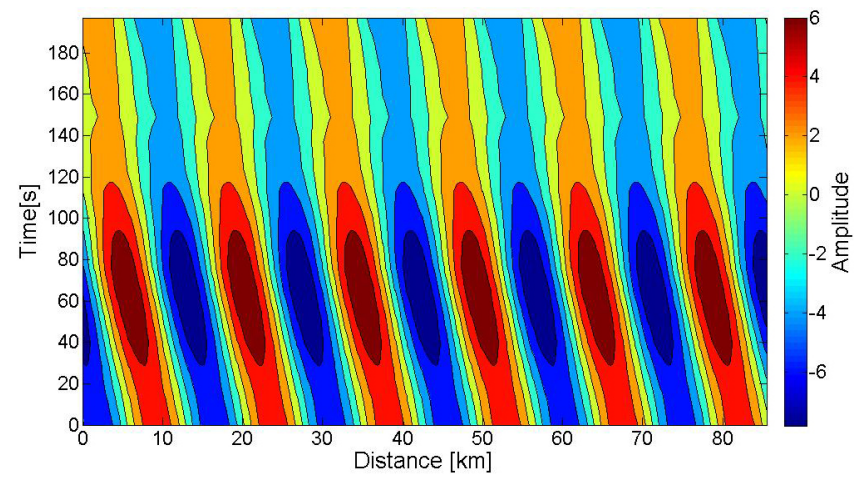

Figure 4. Hovmöller diagrams of the reconstructed wave structure along the propagation direction for consecutive time steps.

on NLC will be to reduce their visibility (Rapp et al., 2002), the bright and dark periodic structures in the NLC, with time scales of minutes, are primarily due to the density perturbations caused by the gravity wave rather than changes in the particle radius due to temperature effects (Jensen and Thomas, 1994). Thus, the relative amplitude of the waves was determined by the amplitude of the NLC intensity variations, determined above, divided by the average Mie scatter of the structured cloud.

Here the background that was fitted to the raw image above has two components, the Rayleigh scatter from the background atmosphere plus the Mie scatter from the clouds. Due to the limited spatial scales of the NLC, the images were filtered to remove high spatial frequencies in order to determine the Rayleigh scatter component. Tests were done on nights with no apparent NLC to ensure that the pure Rayleigh scatter in these images was not affected by the filtering process. Nights with NLC present were filtered, and the Rayleighscattered component was compared to background nights at similar solar angles to ensure that the Mie scattering from the clouds was removed. Dividing the raw NLC image by the filtered "Rayleigh" image resulted in a flat background modulated only by the NLC wave perturbations. Along the direction of propagation, the background fitted to this ratio image represents the ratio of the average Mie plus Rayleigh scatter to Rayleigh scatter. This may be combined with the background from the raw image to obtain the average Mie scatter in the display being analyzed. In this way, the relative amplitude of the NLC Mie scatter could be obtained. Since the wave structures are the result of density enhancements associated with the gravity waves, the relative amplitude of the Mie scatter was taken to be directly proportional to the relative density fluctuation caused by the wave.

\section{Ray-tracing analysis}

In order to examine the possible source regions for the gravity waves observed in our field of view, we used the Gravity Wave Regional or Global Ray Tracer (GROGRAT) model developed by Eckermann and Marks (1997). GROGRAT is a four-dimensional ray-tracing algorithm that traces the evolution of a gravity wave's propagation and amplitude under the effect of background temperature and wind variations in the lower and middle atmosphere (Marks and Eckermann, 1995; Eckermann and Marks, 1997). Here, we launch a spectrum of gravity waves from an array of latitude and longitude points, and utilizes GROGRAT to determine the waves that enter the FOV of the camera at Trondheim.

In this study, the spectrum of waves suggested by Eckermann (1992), which was obtained from their experimental studies, is used. This spectrum consists of waves with uniform amplitudes of $0.3 \mathrm{~m} \mathrm{~s}^{-1}$ and discrete wavelengths of $12.5,25,50,100,200$ and $400 \mathrm{~km}$. Each wavelength is launched with phase speeds of $10,20,30$, and $40 \mathrm{~m} \mathrm{~s}^{-1}$ at each $45^{\circ}$ of azimuth starting from the north. These waves are launched every $5^{\circ}$ of latitude between 60 and $80^{\circ} \mathrm{N}$, and every $10^{\circ}$ of longitude between 0 and $50^{\circ} \mathrm{E}$. The specific parameters entered into GROGRAT for each ray include an initial latitude, longitude, altitude, horizontal wave numbers and initial frequency. The background temperature and pressure fields used in GROGRAT were generated at $2 \mathrm{~km}$ altitude intervals from 0 to $80 \mathrm{~km}$ using the Mass SpectrometerIncoherent Scatter Extended empirical model (MSISE-00) (Hedin, 1991) for the time of the display. Similarly, the wind fields were generated using the empirical Horizontal Wind Model HWM-93 (Hedin et al., 1996), for the time of the display. As the waves propagate upward to $80 \mathrm{~km}$, the trajectories and spatial distributions of waves as a function of time is derived due to the interaction with these fields.

Source regions for gravity waves may lie near the tropopause (Fritts and Alexander, 2003) as in the case of convective activity or orographic lifting. However, they may be the result of secondary generation at higher altitudes by either wave breaking (Holton and Alexander, 1999; Vadas et al., 2003) or as a result of the strong zonal wind shears in the mesosphere (Fritts and Alexander, 2003). To test this, waves were launched from both tropopause heights, $5 \mathrm{~km}$, as well as from $60 \mathrm{~km}$ at the same geographic grid points, and 
the relative amplitudes at NLC heights could be compared with those derived from the NLC image analysis to determine the most probable source altitude. As shown in other analyses, the ray-tracing spectrum differs from the observed NLC spectrum because of the choice of initial spectrum for the ray tracing and possible limitations in the range of periods and wavelengths observed in the NLC images (this is evident in the difference in the respective histograms). The ray-tracing results are presented to indicate the relative amplitude of waves from the different heights and not to provide comparisons between the spectra.

\section{Results}

The characteristic horizontal wave parameters such as wavelength, phase velocity, period, propagation direction and amplitude of the gravity waves were inferred from the NLC images, and a histogram of these wave parameters and the direction of propagation of the waves are shown in Figs. 5 and 8, respectively. For comparison, histograms of the wave parameters from the ray-traced waves that reached the NLC altitude from the source region of 5 and $60 \mathrm{~km}$ are shown in Figs. 6 and 7, respectively.

The histogram of wave structures derived from the NLC images (Fig. 5a) shows that there is a strong preference for structures with scales less than $35 \mathrm{~km}$, with an average wavelength of $24 \mathrm{~km}$. However, the characteristic horizontal wavelengths for the ray-traced waves launched from both the 5 and $60 \mathrm{~km}$ altitudes show that while these short wavelength waves do propagate to NLC heights, both distributions are similar and increase with wavelength. Thus the ray tracing shows that most of the waves reaching the mesosphere from either tropospheric or stratospheric sources have wavelengths greater than $40 \mathrm{~km}$. This discrepancy is likely due to the spatial constraints of the camera. Due to the size of the FOV $\left(53^{\circ} \times 41^{\circ}\right)$ of the NLC camera, the maximum observable horizontal wavelength is less than $100 \mathrm{~km}$ (Pautet et al., 2011). Thus, very long waves will not be observable as a modulation of the intensity within a single image and will not be identified as waves. Similarly, the high levels of Rayleigh scattering present in our high latitude images further restrict our usable FOV and will bias us towards shorter period waves.

The observed phase speeds of the waves observed in the NLC (Fig. 5b) and those resulting from the wave tracing (Figs. 6b and 7b) all average around $31 \mathrm{~m} \mathrm{~s}^{-1}$. However, whereas the ray-traced waves from 5 and $60 \mathrm{~km}$ both show a peak in the distribution near the average value, the waves observed in the NLC have a broader range of phase speeds, with most waves having a phase speed between 10 and $20 \mathrm{~m} \mathrm{~s}^{-1}$. Conversely, most of the waves detected in the NLC and those traced upward from both 5 and $60 \mathrm{~km}$ (Figs. 5c, 6c and $7 \mathrm{c}$ ) have observed periods below $20 \mathrm{~min}$. However, the NLC waves have nearly and equal percentage of events with
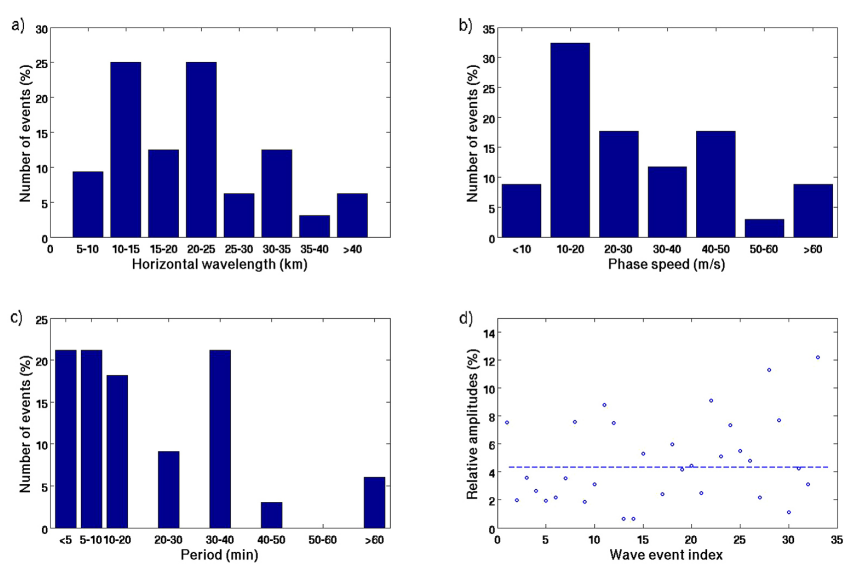

Figure 5. Histogram of the (a) horizontal wavelength, (b) phase speed, (c) period, and (d) relative amplitudes (as determined in Sect. 3.2) for each wave event studied using the camera in Trondheim (TRD).
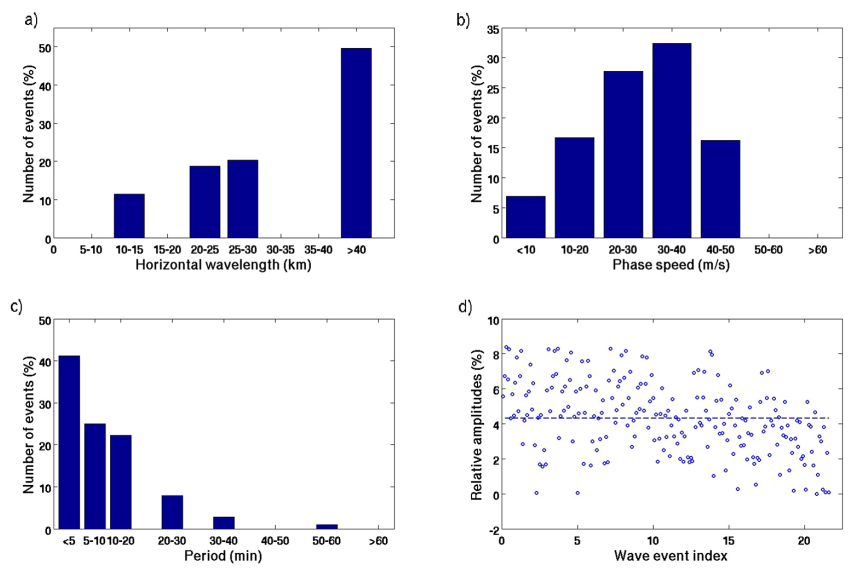

Figure 6. Histograms of the (a) horizontal wavelength, (b) phase speed, (c) period, and (d) relative amplitude (as determined in Sect. 3.2) for each wave event traced from 5 to $80 \mathrm{~km}$.

observed periods near 30 to $40 \mathrm{~min}$, resulting in an average observed period of $24 \mathrm{~min}$. In contrast, the waves traced upward from 5 and $60 \mathrm{~km}$ predominantly occur with observed periods less than $5 \mathrm{~min}$. In addition, the number of waves at longer observed periods decreases, with few waves occurring at periods longer than $20 \mathrm{~min}$.

Perhaps the most prominent difference between the waves propagating up from the tropopause and those originating in the mesosphere are their relative amplitudes at NLC altitudes, shown in Figs. 6d and 7d, respectively. We see in Fig. $6 \mathrm{~d}$ that the waves originating near the tropopause attain relative amplitudes ranging between $\sim 1$ and $8 \%$, whereas those initiated near $60 \mathrm{~km}$, shown in Fig. 7d, only grow to between $\sim 0.1$ and $0.3 \%$. The relative wave amplitudes observed in the NLC, shown in Fig. 5d, range from $\sim 1$ to $10 \%$. Thus, the amplitude of the majority of waves observed in the 

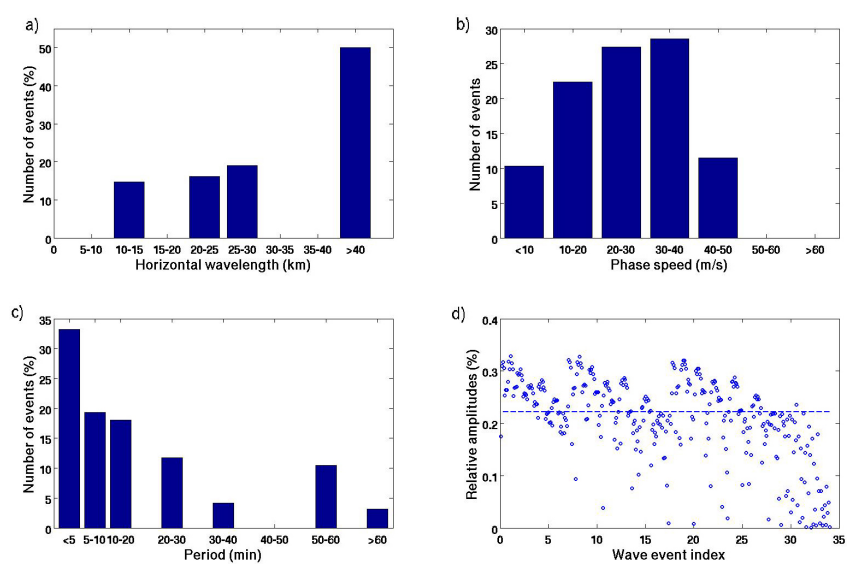

Figure 7. Histograms of the (a) horizontal wavelength, (b) phase speed, (c) period, and (d) relative amplitude (as determined in Sect. 3.2) for each wave event traced from 60 to $80 \mathrm{~km}$.
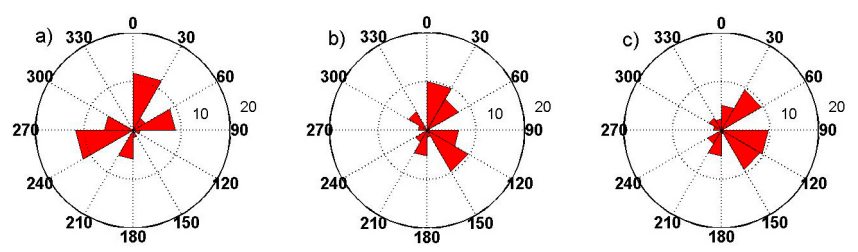

Figure 8. Direction of propagation of gravity waves, (a) for the 34 waves observed in NLC using the camera in TRD, (b) traced from 5 to $80 \mathrm{~km}$, and (c) traced from 60 to $80 \mathrm{~km}$.

NLC Mie scatter would be more consistent with sources near the tropopause. However, this is not to say that waves generated in the stratosphere do not perturb NLC. Rather, there is likely an observational bias to the large amplitude waves from lower altitudes that present the largest contrast and are easiest to detect. It should be noted that the ray-tracing results in this study are through a wind field that represents a climatological average over the NLC observing season at Trondheim. Thus they are not specific to the conditions present during any single observation. However, the observations themselves represent an average over the NLC season during a 4-year period, making the choice of a climatological background atmosphere consistent.

The propagation directions of the ray-traced waves, shown in Fig. 8b and c, indicate that the waves originating from near the tropopause or from $60 \mathrm{~km}$ both have similar eastward directions when they reach NLC altitudes. While the waves observed in the NLC also show a tendency for eastward propagation, Fig. 8 a shows that they tend to be directed more towards the north. Additionally a large percentage of the NLC waves are observed moving in a WSW direction (240-270 ${ }^{\circ}$ azimuth) and towards the ENE (60-90 ${ }^{\circ}$ azimuth) that the ray tracing has indicated are blocked. A null hypothesis $t$ test was applied on the characteristics of these waves propagating in these two "blocked" directions to de- termine whether their wave characteristics differ from the rest of the population. The results, shown in Table 1, indicate that the ENE waves are not significantly different from the general population, but that the WSW waves represent a unique population of waves with shorter wavelengths $\left(\lambda_{\mathrm{avg}}=\right.$ $14.4 \mathrm{~km}$ compared to $24 \mathrm{~km})$ and higher phase speeds $\left(\mathrm{c}_{\mathrm{avg}}=\right.$ $42.4 \mathrm{~m} \mathrm{~s}^{-1}$ compared to $31 \mathrm{~m} \mathrm{~s}^{-1}$ ). Fritts et al. (1993) have shown that these fast, short period waves are associated with local instabilities generated during wave breaking. These instabilities tend to move along the wave front and transverse to the general wave propagation direction, similar to what is observed here.

In order to examine possible source regions for the gravity waves observed in the NLC, the grid points from which the waves were launched at 5 and $60 \mathrm{~km}$ are shown on a map in Fig. 9a and b, respectively. The size of the symbol indicates the percentage of waves originating from a particular grid point that enter the field of view of the NLC imager at Trondheim. The geographical distribution of the wave sources at the two altitudes depict that the coastal regions of Norway at the latitude of $70^{\circ} \mathrm{N}$ are the primary source regions of gravity waves propagating upward from $5 \mathrm{~km}$. The waves propagating upward from $60 \mathrm{~km}$ represent a broader source region that extends eastward and southward of the camera field of view, but, as indicated above, these would cause smaller perturbations in the NLC.

\section{Discussion}

We can compare these climatological results over Norway with the previous work of Pautet et al., 2011, which used imager data from Sweden from 2004 to 2007 that extended to the southern limit of our observations. The comparison of the average horizontal wavelength of the waves shows reasonable agreement, with a mean value of 24 and $25 \mathrm{~km}$ over $\sim 69$ and $\sim 62^{\circ} \mathrm{N}$, respectively. Thus, the wave-like perturbations derived from the NLC images in the summer mesosphere are similar in scale from 60 to $74^{\circ} \mathrm{N}$. In addition, they are similar to mesospheric short-period gravity waves observed in the airglow emissions at middle (Taylor et al., 1998), polar (Nielsen et al., 2006) and equatorial (Nakamura et al., 2003) latitudes, where peak horizontal wavelengths around $25-30 \mathrm{~km}$ were found.

The average observed phase speed for the Trondheim data was found to be $31 \mathrm{~m} \mathrm{~s}^{-1}$, which also compares favorably with the average value of $27 \mathrm{~m} \mathrm{~s}^{-1}$ found by Pautet et al. (2011) for the summertime data taken from Stockholm. Similarly, there is no significant difference in the average observed periods of the two data sets: $24 \mathrm{~min}$ at $\sim 69^{\circ} \mathrm{N}$ and $22 \mathrm{~min}$ at $\sim 62^{\circ} \mathrm{N}$. However, these observed phase speeds measured using NLC data during the high latitude summer are smaller than other previous long-term studies of gravity waves observed at slightly higher altitude in the airglow emission. For example, Taylor et al. (1997) 
Table 1. Result of the $t$ test; average (Avg), standard deviation (SD), $t$ test statistic $\left(t_{\text {stat }}\right)$, df and $p$ stands for average, standard deviation, test statistic, degree of freedom and $p$ value respectively. For the average values and the standard deviations, wavelength is in units of km, phase speed in units of $\mathrm{m} \mathrm{s}^{-1}$, and period in units of minutes.

$t$ test between the waves that propagate east (60-90) and the rest of the waves excluding SW wave

\begin{tabular}{lrrrrrrr}
\hline & Average values for east wave & SD for east wave & Avg for the other & SD for the other & $t_{\text {stat }}$ & df & $p$ \\
\hline Wavelength & 23.72 & 4.99 & 28.73 & 19.35 & -1.0265 & 22.75 & $68.45 \%$ \\
Phase speed & 23.04 & 13.66 & 28.29 & 18.51 & -0.7489 & 11.42 & $53.09 \%$ \\
Period & 21.68 & 11.83 & 25.03 & 23.08 & -0.4670 & 17.3 & $17.3 \%$ \\
\hline
\end{tabular}

$t$ test between the waves that propagate SW and the rest of the waves

\begin{tabular}{lrrrrrrr}
\hline & Average values for SW wave & SD for SW wave & Avg for the other & SD for the other & $t_{\text {stat }}$ & df & $p$ \\
\hline Wavelength & 14.42 & 5.64 & 27.53 & 17.05 & -3.3667 & 31.95 & $99.8 \%$ \\
Phase speed & 42.4 & 27.67 & 27.03 & 17.35 & 1.5599 & 10.357 & $85.12 \%$ \\
Period & 23.94 & 51.94 & 24.23 & 20.76 & -0.0159 & 8.9363 & $1.24 \%$ \\
\hline
\end{tabular}

$t$ test between the waves that propagate SW and eastward (60-90)

\begin{tabular}{lrrrrrrr}
\hline & Average values for SW wave & SD for SW wave & Avg for the east & SD for the east & $t_{\text {stat }}$ & df & $p$ \\
\hline Wavelength & 14.42 & 5.64 & 23.72 & 4.99 & -3.3516 & 11.779 & $99.41 \%$ \\
Phase speed & 42.4 & 27.67 & 23.04 & 13.66 & 1.7964 & 12.289 & 90.03 \\
Period & 23.94 & 51.94 & 21.68 & 11.83 & 0.126 & 9.204 & 9.73 \\
\hline
\end{tabular}
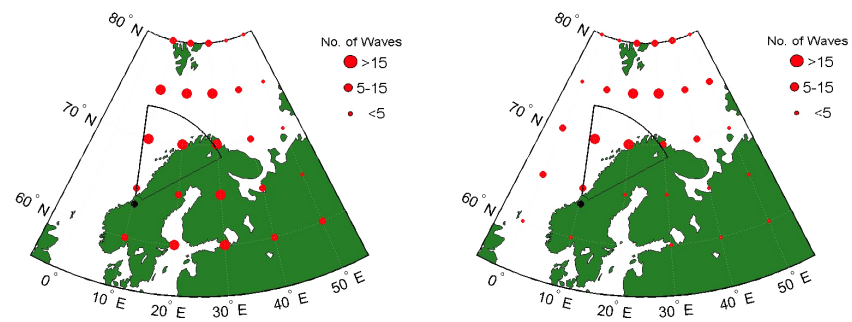

Figure 9. Geographic source regions for waves appearing in the FOV of the camera at NLC altitudes. The left panel shows the starting location of waves that have propagated upward from $5 \mathrm{~km}$ and entered the FOV. The right panel shows the location of waves originating at $60 \mathrm{~km}$ that enter the FOV. For the grid points left blank there are no waves that enter the FOV of camera at NLC altitudes.

and Nakamura et al. (2003) found an average value of approximately $48 \mathrm{~m} \mathrm{~s}^{-1}$ at low latitudes $\left(2^{\circ} \mathrm{S}\right)$, and Hecht et al. (2001) found a mean value of $50 \mathrm{~m} \mathrm{~s}^{-1}$ at middle latitudes $\left(40^{\circ} \mathrm{N}\right)$. Similarly, the high latitude measurements in the Southern Hemisphere at Halley $\left(76^{\circ} \mathrm{S}\right)$ found a mean value of $48 \mathrm{~m} \mathrm{~s}^{-1}$ (Nielsen et al., 2009) during winter. Correspondingly, the observed periods found in these studies are typically on the order of $8-10 \mathrm{~min}$. However, Ejiri et al. (2003) found an average value of $35 \mathrm{~m} \mathrm{~s}^{-1}$ at mid latitude $\left(40^{\circ} \mathrm{N}\right)$, similar to this work. This wide range of values could be due to different gravity wave sources, for example orographic versus frontal generation, where the observed phase speeds would be Doppler shifted due to speed of the source relative to the observer.
The directions of propagation of the waves observed in the NLC show that the majority of the waves in Norway are propagating towards the north and northeast at azimuths between 0 and $30^{\circ}$, but there is a separate population of small-scale fast waves propagating towards the southwest between 240 and $270^{\circ}$ of azimuth. Similarly, Pautet et al. (2011) found that $60 \%$ of the waves in Sweden propagate towards the north or the northeast directions, but did not observe the waves moving towards the southwest. This matches the propagation directions found for the waves launched from 5 and $60 \mathrm{~km}$, where the SW direction is blocked by the wind field. Given this blocking, and the fact that the waves we observe moving towards the SW have significantly shorter wavelengths and higher phase speeds than those propagating northward or north-eastward, indicate that these are formed as a result of local, transverse instabilities accompanying wave breaking (Fritts et al., 1993). The shorter observing times available each night at Trondheim as compared to Stockholm, as well as the more restricted field of view resulting from the higher levels of Rayleigh scatter means that these fast moving, short scale instabilities were more likely to have been picked for analysis.

Viewing along tilted phase fronts of gravity, waves could artificially enhance the density perturbation inferred from the images and bias the observations to waves moving towards the north (Jensen and Thomas, 1994). However, for the range of wavelengths and periods observed here, the work of Jensen and Thomas (1994) indicates that such a bias would not occur for elevation angles between 10 and $16^{\circ}$ used here. In fact, that work shows that for these elevation angles, viewing geometry effects would reduce the NLC Mie 
scatter amplitudes relative to the density fluctuations of the wave by over a factor of 2 . Thus, the amplitudes reported here represent a lower limit to the wave amplitudes, further strengthening the argument that the waves observed in the NLC originate from lower altitudes.

\section{Conclusions}

The climatology of summertime gravity waves detected in NLC between 64 and $74^{\circ} \mathrm{N}$ is similar to that observed between 60 and $64^{\circ} \mathrm{N}$ by Pautet et al. (2011). While the average horizontal wavelengths observed in these two studies agree with previous results from airglow imaging, the observed phase speeds are much slower, and the observed periods correspondingly longer, than those observed in the airglow at lower latitudes and during high-latitude winter. This could be due to differences in the gravity wave sources, or an observational bias brought on by the more restrictive fields of view available to the NLC cameras when compared to the nearly all-sky airglow observations. The gravity waves observed in the NLC north of $64^{\circ} \mathrm{N}$ continue to propagate towards the north or northeast as they have been observed to do south of $64^{\circ} \mathrm{N}$. However, the unique population of fast, short wavelength waves propagating towards the SW is consistent with transverse instabilities generated in situ by breaking gravity waves. Finally, comparison of the relative amplitude of the waves observed in the NLC Mie scatter with ray-tracing results show that waves propagating from the tropopause, rather than those resulting from secondary generation in the stratosphere or mesosphere, are more likely to be the sources of the prominent wave structures observed in the NLC. The geographic distribution of the waves generated near the tropopause that can be ray traced into the observational field of view identify the coastal region of Norway along the latitude of $70^{\circ} \mathrm{N}$ as the primary source region. As this is the region where many of the polar low pressure systems make landfall, interaction of the frontal systems with the coastal mountainous terrain is a likely generation mechanism for the prominent wave structures observed in the NLC near the mesopause.

Acknowledgements. We would like to thank F.-J. Lübken, director of IAP, for the opportunity of carrying part of the present work at IAP. This study was supported by the Research Council of Norway under contracts 191747/V30 and under CoE contract 223252/F50.

Edited by: W. Ward

\section{References}

Baumgarten, G., Fiedler, J., Fricke, K. H., Gerding, M., Hervig, M., Hoffmann, P., Müller, N., Pautet, P.-D., Rapp, M., Robert, C., Rusch, D., von Savigny, C., and Singer, W.: The noctilucent cloud (NLC) display during the ECOMA/MASS sounding rocket flights on 3 August 2007: morphology on global to local scales, Ann. Geophys., 27, 953-965, doi:10.5194/angeo-27-953-2009, 2009a.

Baumgarten, G., Gerding, M., Kaifler, B., and Müller, N.: A transEuropean network of cameras for observation of noctilucent clouds from $37^{\circ} \mathrm{N}$ to $69^{\circ} \mathrm{N}$, Proceedings 19 th ESA Symposium on European Rocket and Ballon Programmes and Related Research, Bad Reichenhall, Germany, 7-11 June 2009, 2009b.

Chandran, A., Rusch, D. W., Palo, S. E., Thomas, G. E., and Taylor, M. J.: Gravity wave observations in the summertime polar mesosphere from the cloud imaging and particle size (CIPS) experiment on the AIM spacecraft, J. Atmos. Sol.-Terr. Phys., 71, 285-288, 2009.

Chandran, A., Rusch, D. W., Merkel, A. W., Palo, S. E., Thomas, G. E., Taylor, M. J., Bailey, S. M., and Russell III, J. M.: Polar Mesospheric Cloud structures observed from the CIPS experiment on the AIM spacecraft: atmospheric gravity waves as drivers for longitudinal variability in PMC occurrence, J. Geophys. Res., 115, D13102, doi:10.1029/2009JD013185, 2010.

Eckermann, S. D.: Ray-tracing simulation of the global propagation of inertia gravity waves through the zonally averaged middle atmosphere, J. Geophys. Res. , 97 , 15849-15866, doi:10.1029/92JD01410, 1992.

Eckermann, S. D. and Marks C. J.: GROGRAT: A new model of the global propagation and dissipation of atmospheric gravity waves, Adv. Space Res. 20, 1253-1256, 1997.

Ejiri, M. K., Shiokawa, K., Ogawa, T., Igarashi, K., Nakamura, T., and Tsuda, T.: Statistical study of short-period gravity waves in $\mathrm{OH}$ and OI nightglow images at two separated sites, J. Geophys. Res., 108, 4679, doi:10.1029/2002JD002795, 2003.

Espy, P. J. and Stegman, J.: Trends and variability of mesospheric temperature at high-latitudes, Phys. Chem. Earth, 27, 543-553, 2002.

Espy, P. J., Jones, G. O. L., Swenson, G. R., Tang, J., and Taylor, M. J.: Seasonal variations of the gravity-wave momentum flux in the Antarctic mesosphere and lower thermosphere, J. Geophys. Res., 109, D23109, doi:10.1029/2003JD004446, 2004.

Espy, P. J., Hibbins, R. E., Swenson, G. R., Tang, J., Taylor, M. J., Riggin, D. M., and Fritts, D. C.: Regional variations of mesospheric gravity-wave momentum flux over Antarctica, Ann. Geophys., 24, 81-88, doi:10.5194/angeo-24-81-2006, 2006.

Fiedler, J., Baumgarten, G., and Lübken, F. -J.: NLC observations during one solar cycle above ALOMAR, J. Atmos. Sol.-Terr. Phys., 71, 424, 2009.

Fritts, D. C. and Alexander, M. J.: Gravity wave dynamics and effects in the middle atmosphere, Rev. Geophys., 41, 1003, doi:10.1029/2001RG000106, 2003.

Fritts, D. C. and Luo, Z. G.: Dynamical and radiative forcing of the summer mesopause circulation and thermal structure: 1. Mean solstice conditions, J. Geophys. Res., 100, 3119-3128, 1995.

Fritts, D. C., Isler, J. R., Thomas, G. E., and Andreassen, Ø: Wave breaking signatures in noctilucent clouds, Geophys. Res. Lett., 20, 2039-2042, doi:10.1029/93GL01982, 1993.

Gadsden, M. and Schröder, M.: Noctilucent Clouds, SpringerVerlag, Berlin, 165 pp., 1989.

Garcia, R. G. and Solomon, S.: The effect of breaking gravity waves on the dynamics and chemical composition of the mesosphere and lower thermosphere, J. Geophys. Res., 90, 3850-3868, 1985. 
Garcia, R. R. and Boville, B. A.: "Downward control" of the mean meridional circulation and temperature distribution of the polar winter stratosphere, J. Atmos. Sci., 51, 2238-2245, 1994.

Garcia, F. J., Taylor, M. J., and Kelley, M. C.: Two-dimensional spectral analysis of mesospheric airglow image data, Appl. Optics, 36, 7374-7385, 1997.

Hamilton, K.: Comprehensive modeling of the middle atmosphere climate: some recent results, Clim. Dynam., 11, 223-241, 1995.

Hamilton, K.: Comprehensive meteorological modeling of the middle atmosphere: a tutorial review, J. Atmos. Sol.-Terr. Phy., 58, 1591-1627, 1996.

Haurwitz, B.: Wave formations in noctilucent clouds, Planet. Space Sci., 5, 92-98, 1961.

Hecht, J. H., Walterscheid, R. L., Hickey, M. P., and Franke, S. J.: Climatology and modeling of quasi-monochromatic atmospheric gravity waves observed over Urbana Illinois, J. Geophys. Res., 106, 5181-5195, 2001.

Hedin, A. E.: Extension of the MSIS thermospheric model into the middle and lower atmosphere, J. Geophys. Res., 96, 1159-1172, 1991.

Hedin, A. E., Fleming, E. L., Manson, A. H., Schmidlin, F. J., Avery, S. K., Clark, R. R., Franke, S. J., Fraser, G. J., Tsuda, T., Vial, F., and Vincent, R. A.: Empirical wind model for the upper, middle and lower atmosphere, J. Atmos. Sol.-Terr. Phy., 58, 1421-1447, 1996.

Hines, C. O.: Internal atmospheric gravity waves, Can. J. Phys., 38, 1441-1481, 1960.

Hines, C. O., Adams, G. W., Brosnahan, J. W., Djuth, F. T., Sulzer, M. P., Tepley, C., A., and Van Baelen, J. S.: Multi-instrument observations of mesospheric motions over Arecibo: comparisons and interpretations, J. Atmos. Terr. Phys., 55, 241-287, 1993.

Holton, J. R.: The role of gravity wave induced drag and diffusion in the momentum budget of the mesosphere, J. Atmos. Sci., 39, 791-799, 1982.

Holton, J. R.: The influence of gravity wave breaking on the general circulation of the middle atmosphere, J. Atmos. Sci., 40, 2497-2507, 1983.

Holton, J. R. and Alexander, M. J.: Gravity waves in the mesosphere generated by tropospheric convection, Tellus B, 51, 45-58, 1999.

Jensen, E. J. and Thomas, G. E.: Numerical simulation of the effects of gravity waves on noctilucent clouds, J. Geophys. Res., 99, 3421-3430, 1994.

Lindzen, R. S.: Turbulence and stress owing to gravity wave and tidal breakdown, J. Geophys. Res., 86, 9707-9714, 1981.

Lübken, F.-J., Jarvis, M. J., and Jones, G. O. L.: First in situ temperature measurements at the Antarctic summer mesopause, Geophys. Res. Lett., 26, 3581-3584, 1999.

Luo, Z. G., Fritts, D. C., Portmann, R. W., and Thomas, G. E.: Dynamical and radiative forcing of the summer mesopause circulation and thermal structure: 2. Seasonal-variations, J. Geophys. Res., 100, 3129-3137, 1995.

Marks, C. J., and S. D. Eckermann: A Three-Dimensional Nonhydrostatic Ray-Tracing Model for Gravity Waves: Formulation and Preliminary Results for the Middle Atmosphere., J. Atmos. Sci., 52, 1959-1984, 1995.

Nakamura, T. A., Tsuda, T., Admiranto, T., Achmad, A. G., and Suranto, E.: Mesospheric gravity waves over a tropical convective region observed by $\mathrm{OH}$ airglow imaging in Indonesia, Geophys. Res. Lett., 30, 1882, doi:10.1029/2003GL017619, 2003.
Nielsen, K., Taylor, M. J., Pautet, P.-D., Fritts, D. C., Mitchell, N., Beldon, C., Williams, B. P., Singer, W., Schmidlin, F. J., and Goldberg, R. A.: Propagation of short-period gravity waves at high-latitudes during the MaCWAVE winter campaign, Ann. Geophys., 24, 1227-1243, doi:10.5194/angeo-241227-2006, 2006.

Nielsen, K., Taylor, M. J., Hibbins, R. E., and Jarvis, M. J.: Climatology of short-period mesospheric gravity waves over Halley, Antarctica $\left(76^{\circ} \mathrm{S}, 27^{\circ} \mathrm{W}\right)$, J. Atmos. Sol.-Terr. Phy., 71, 991-1000, 2009.

Pautet, D. and Moreels, G.: Ground-based satellite-type images of the upper-atmosphere emissive layer, Appl. Optics, 41, 823-831, doi:10.1364/AO.41.000823, 2002.

Pautet, P.-D., Taylor, M. J., Liu, A. Z., and Swenson, G. R.: Climatology of short-period gravity waves observed over northern Australia during the Darwin area wave experiment (DAWEX) and their dominant source regions, J. Geophys. Res., 110, D03S90, doi:10.1029/2004JD004954, 2005.

Pautet, P.-D., Stegman, J., Wrasse, C. M., Takahashi, H., and Taylor, M. J.: Analysis of gravity waves structures visible in noctilucent cloud images, global perspectives on the aeronomy of the summer mesopause region, 8th international workshop on layered phenomena in the mesopause region, J. Atmos. Sol.-Terr. Phy., 73, 2082-2090, doi:10.1016/j.jastp.2010.06.001, 2011.

Rapp, M., Lübken, F.-J., Müllemann, A., Thomas, G., and Jensen, E.: Smallscale temperature variations in the vicinity of NLC: experimental and model results, J. Geophys. Res., 107, 4392, doi:10.1029/2001JD001241, 2002.

Rind, D., Suozzo, R., Balachandran, N. K., Lacis, A., and Russell, G.: The GISS global climate-middle atmosphere model: Part I: Model structure and climatology, J. Atmos. Sci., 45, 329-370, 1988.

Suzuki, S., Shiokawa, K., Hosokawa, K., Nakamura, K., and Hocking, W. K.: Statistical characteristics of polar cap mesospheric gravity waves observed by an all-sky airglow imager at Resolute Bay, Canada, J. Geophys. Res., 114, A01311, doi:10.1029/2008JA013652, 2009.

Suzuki, S., Lübken, F.-J., Baumgarten, G, Kaifler, N., Eixmann, R., Williams, B. P., and Nakamura, T.: Vertical propagation of a mesoscale gravity wave from the lower to the upper atmosphere, J. Atmos. Sol.-Terr. Phys., 97, 29-36, doi:10.1016/j.jastp.2013.01.012, 2013.

Taylor, M. J. and Henriksen, K.: Gravity wave studies at polar latitudes, in: Electromagnetic Coupling in the Polar Clefts and Caps, edited by: Sandholt, P. E. and Egeland, A., Kluwer Academic Publications, Dordrecht, the Netherlands, 421-434, 1989.

Taylor, M. J., Pendleton Jr., W. R., Clark, S., Takahashi, H., Gobbi, D., and Goldberg, R. A.: Image measurements of shortperiod gravity waves at equatorial latitudes, J. Geophys. Res., 102, 26283-26299, 1997.

Taylor, M. J., Seo, S. H., Nakamura, T., Tsuda, T., Fukunishi, H., and Takahashi, Y.: Long base-line measurements of short-period mesospheric gravity waves during the SEEK campaign, Geophys. Res. Lett., 25, 1797-1800, 1998.

Taylor, M. J., Pautet, P.-D., Zhao, Y., Randall, C. E., Lumpe, J., Bailey, S. M., Carstens, J., Nielsen, K., Russell III, James M., and Stegman, J.: High-latitude gravity wave measurements in noctilucent clouds and polar mesospheric clouds, in Aeronomy of the Earth's Atmosphere and Ionosphere, IAGA Special Sopron 
Book Series, Volume 2, Part 1, 93-105, doi:10.1007/978-94-0070326-1_7, 2011.

Thomas, G. E.: Mesospheric clouds and the physics of the mesopause region, Rev. Geophys., 29, 553-575, 1991.

Vadas, S. L., Fritts, D. C., and Alexander, M. J.: Mechanisms for the generation of secondary waves in wave breaking regions, J. Atmos. Sci., 60, 194-214, 2003.
Vincent, R. A.: Gravity-wave motions in the mesosphere, J. Atmos. Terr. Phys., 46, 119-128, 1984.

Witt, G.: Height, structure and displacements of noctilucent clouds, Tellus, 14, 1-18, 1962. 